\title{
The intellectual profiles of high functioning elderly persons with an autism spectrum disorder
}

\author{
Annelies A. Spek ${ }^{1 *}$, Loes M. Ham² and Frederique E.M. Geven ${ }^{3}$
}

*Correspondence: a.spek@autismeexpertise.nl

${ }^{1}$ Autism Expertise Center, The Netherlands. ${ }^{2}$ GGZ Oost-Brabant, Veghel, The Netherlands.

${ }^{3}$ GGZ Eindhoven, Eindhoven, The Netherlands.

\begin{abstract}
Research into the cognitive profiles of older adults with ASD is limited. We know little about how aging affects individuals with ASD and how this influences their needs. The present study is the first to examine intelligence profiles in older adults with ASD. WAIS-III performance of 23 elderly with ASD and 23 neurotypical older persons was examined. The two groups were matched on age and level of education. Results showed highly similar intelligence profiles, with the exception of processing speed index, on which the older adults with ASD performed weaker than the neurotypical control group. This was caused by impairment on the subscale Digit symbol-coding, which was hypothesized to be due to a local information processing style and problems in set shifting.
\end{abstract}

Keywords: ASD, elderly, WAIS-III, central coherence, set shifting

\section{Introduction}

Autism is a lifelong developmental disorder that affects an individual's functioning in multiple areas. Research into autism spectrum disorders (ASD) has mainly been focused on children and adolescents, which is understandable given the historical context and the fact that autism is a developmental disorder. In recent years, interest in adults with ASD has grown, but only little is known about ASD in the elderly. We do not know how aging affects people with ASD and how this affects their needs. For one thing, it is unclear if the aging process of adults with ASD is similar to that of the general population.

It is expected that the population of elderly individuals with ASD will grow substantially in the coming years, as autistic spectrum disorders are increasingly recognized in adults and in elderly individuals. Therefore, it is important to gain knowledge about ASD in older individuals and to learn about their strengths and weaknesses and their specific needs. Existing research into elderly persons with ASD is limited to several case report studies and one study in which executive functions and memory has been examined. Two of the case studies described five older adults with Asperger syndrome, aged between 66 and $84[13,17]$. Findings suggested that older adults with Asperger syndrome often lead relatively successful lives. For instance, three of the five were married, had raised families and had been employed. Other research also reported improvement over time in individuals with ASD in symptomatology and maladaptive behaviors. This seems mostly due to acquisition of compensatory skills [21].

Although behavioral symptoms seem to become somewhat less intrusive over time, it is not clear whether this is linked to cognitive improvement. Two studies in which changes from childhood to adulthood was examined, showed a decline in performance IQ and improvements in verbal IQ $[12,16]$. Results also showed a decline in full scale IQ for the individuals with autism, but not for the adults with Asperger syndrome. However, in these two studies, almost all individuals had a below average intelligence and they did not examine elderly persons with ASD. In fact, only one paper exists in which cognitive characteristics of elderly adults with ASD were examined [8]. The authors compared 23 individuals with high functioning autism with 23 healthy controls on executive functioning and memory. The participants ranged in age from 51 to 83 years. Results suggested impairments in the autistic sample in sustained attention, working memory and fluency. No group differences were found in processing speed, cognitive flexibility, planning, visual memory and verbal memory. Thus, the robust findings 
Spek et al., Journal of Autism 2017,

of impaired planning and cognitive flexibility in autism [11] may not apply to the elderly population. This may be due to compensatory strategies of individuals with autism, which might improve over time. Another possibility is that the impairment of individuals with autism in some way 'catches up with' the increasing impairment in several cognitive areas that characterizes normal aging. It has also been hypothesized that the larger brain volume, which has been suggested in autism, may be a protective factor for age-related brain changes $[5,25]$. Based on these theoretical assumptions and the findings of [8], it appears most likely that aging in people with autism is the same as in typical individuals in some cognitive domains, while in other cognitive domains different aging patterns are shown. With regard to further research into cognitive profiles of elderly persons with ASD, it is worth noting that the study of [8] does suffer some limitations. For example, no clinical interviews were used in the diagnostic process and the number of participants older than 60 years of age was relatively small. Further research is needed in order to more thoroughly examine cognitive strengths and weaknesses of autism in elderly subjects. For this reason, we decided to investigate the intelligence profiles of individuals with ASD aged 60 years and older and compare the results to an agematched neurotypical control group.

\section{Methods}

\section{Participants and procedure}

23 Elderly adults with ASD were recruited from the Psychiatric Center for the Elderly, the Netherlands. All participants had undergone a standardized diagnostic process. The autism spectrum disorder was diagnosed by means of evaluation of historic and current symptomatology by a trained and experienced psychologist. If possible, an older sibling was interviewed in order to investigate the early childhood of the participant. In other cases, we relied on other family members, partners or other informants. When no information of early childhood development could be gained we used the current algorithm of the Dutch version of the Autism Diagnostic Interview, Revised version (ADI-R), [15]. We also conducted a semi-structured interview with all participants in order to assess the ASD criteria of the DSM-IV-TR [1]. For each diagnostic criterion, a standard primary question was asked, followed by questions to clarify whether the participant met the criteria of the given item. This semi-structured interview has been used for diagnostic classification in previous studies e.g. [23,24]. Finally, the diagnoses were based on a clinical judgement of all the information that was gathered. Only those participants who met DSM-IV-TR criteria of the autistic disorder, Asperger syndrome or pervasive developmental disorder, not otherwise specified (PDD-NOS), were included in the present study. We decided to include all individuals with a diagnosis on the autism spectrum, based on the recent notion that there is insufficient evidence for a valid distinction between the diagnostic subtypes within the autism spectrum [28].
This is in line with recent developments in DSM-5 criteria of neurodevelopmental disorders that describe that autism is best represented as a single diagnostic category [2]. Participants were eligible to participate if they met the following criteria: (1) age 60 years and older; (2) having a diagnosed autism spectrum disorder (3) being male, in order to create a homogenous group. Exclusion criteria included: (1) genetic conditions or other neurodevelopmental, neurodegenerative or psychiatric disorders; (2) being institutionalized; (3) having a below-average intelligence (scoring less than 80 in full scale intelligence, as measured by the WAIS-III [26]). 23 Neurotypical control subjects were recruited from the general population through advertisements in local newspapers and by word of mouth. Healthy controls were not included in the present study if they had a history of psychiatric illness or if autism ran in the family.

The ASD group and the neurotypical group were closely matched on age $(t(44)=-0.114, p=0.91)$ and level of education $\left(X^{2}(3)=0.695, p=0.87\right)$. In the Dutch educational system, four levels of secondary education can be distinguished: low, middle, high and (vocational) college. In the present study, we matched both groups based on those four educational levels. Individuals who were not able to attend secondary education were also classified under 'low educational level' (see Table 1).

Table 1. Matching Variables $(\mathrm{N}=46)$.

\begin{tabular}{lllll}
\hline & ASD $(\mathrm{N}=23)$ & Control $(\mathrm{N}=23)$ & Statistic & p-value \\
\hline Mean age & $66.1(6.7)$ & $66.3(6.1)$ & $\mathrm{t}(44)=-0.114$ & 0.91 \\
$\begin{array}{l}\text { Level of } \\
\text { education }\end{array}$ & -- & -- & $\chi^{2}(3)=0.695$ & 0.87 \\
Low & $4(17 \%)$ & $3(13 \%)$ & -- & -- \\
Middle & $6(26 \%)$ & $6(26 \%)$ & -- & -- \\
High & $10(44 \%)$ & $9(39 \%)$ & -- & -- \\
College & $3(13 \%)$ & $5(22 \%)$ & -- & -- \\
\hline
\end{tabular}

Both the elderly participants with ASD and the participants in the neurotypical control group were on average 66 years of age. $87 \%$ Of the individuals with ASD has (had) a relationship, which is a relatively high percentage. However, most of the participants with ASD who have a relationship also reported problems in this area. Furthermore, $26 \%$ of the older participants with ASD in our sample have a relative with a similar diagnosis. This is in line with the review of [10], who state that diagnosis of the elderly with ASD is often prompted by an ASD diagnosis of a relative. The group characteristics are illustrated in Table 2.

\section{Measures \\ WAIS-III}

The intelligence profile was assessed using the Dutch translation of the WAIS-III [26]. Compared to WAIS-II, significant modifications and structural changes have been made. Three 
Spek et al., Journal of Autism 2017,

http://www.hoajonline.com/journals/pdf/2054-992X-4-3.pdf

Table 2. General characteristics of the ASD group $(\mathrm{N}=23)$.

\begin{tabular}{lll}
\hline & N & $\%$ \\
\hline Marital status & & \\
\hline Married/cohabiting & 14 & 61 \\
Divorced, new relationship & 3 & 13 \\
Divorced & 1 & 4 \\
Widowed & 2 & 9 \\
Single & 3 & 13 \\
\hline Relationship problems & & \\
\hline Yes & 14 & 61 \\
No & 9 & 39 \\
\hline Relative(s) with ASD & & \\
\hline Yes & 6 & 26 \\
No & 14 & 61 \\
Suspected, not formally diagnosed & 3 & 13 \\
\hline Able to work at level of educational achievement \\
\hline Yes & 15 & 65 \\
No & 8 & 35 \\
\hline
\end{tabular}

new subtests were added: Matrix Reasoning, Symbol Search and Letter-Number Sequencing. The WAIS-III has a factor structure that presents the best representation of the factors underlying intelligence $[3,19]$.

Furthermore, the norms have been improved to correct for the Flynn-effect that appeared to be present in the Dutch WAIS-R. WAIS-III has excellent psychometric properties [20] and has been validated for the Dutch population [26]. It was not possible to use the WAIS-IV, since at the time of this study, there was no Dutch translation available. In order to reduce the Flynn-effect of the WAIS-III, an update of the Dutch norms has been used [27].

\section{Results}

To test the hypothesis of differences in total IQ, index scores and subtest scores between the two groups, an univariate analyses of variance (ANOVA) was performed, using the diagnosis as the dependent variable and the WAIS-III scores as independent variable. The analyses showed that the assumptions of homogeneity were met, except for the subscale 'information'. Therefore, a more conservative alpha level of 0.01 was set for this subscale.

\section{Total IQ and index scores}

The results of the full scale IQ score and the index scores are presented in Table 3. The analyses showed that the full scale IQ of the individuals with ASD and the control group differed less than three points, which is a non-significant difference $(p=0.52)$. On index level, the two groups did not significantly differ in verbal comprehension $(p=0.49)$, perceptual organization $(p=0.67)$ and working memory $(p=0.20)$. The analyses did reveal a significant difference in processing speed $(p=0.04)$. The ASD group scored significantly lower on this index scale
Table 3. Mean standardized scores total IQ and Index scales.

\begin{tabular}{llll}
\hline & ASD (N=23) & Control $(\mathbf{N}=23)$ & Statistic \\
\hline Full Scale IQ & $107.4(15.7)$ & $110.3(13.6)$ & $\begin{array}{l}F(1,44)=0.426, \\
p=0.517\end{array}$ \\
& & & $F(1,44)=0.492$, \\
Verbal & $107.5(12.0)$ & $109.8(10.3)$ & $\begin{array}{l}F .487 \\
\text { Comprehension }\end{array}$ \\
Perceptual & $107.6(16.0)$ & $105.8(12.6)$ & $\begin{array}{l}F(1,44)=0.184, \\
p=0.670\end{array}$ \\
Organization & & & $\begin{array}{l}F(1,44)=1.686, \\
p=0.201\end{array}$ \\
Working & $107.0(16.1)$ & $112.7(13.5)$ & $F(1,44)=4.294$, \\
Memory & & & $p=0.044 *$ \\
Processing & $99.3(17.2)$ & $108.0(10.5)$ & \\
Speed & & & \\
\hline
\end{tabular}

${ }^{\star} \mathrm{p}<0.05 ;{ }^{* *} \mathrm{p}<0.01$

than the neurotypical control group.

\section{Subtest scores}

As can be seen in Table 4, performance on Vocabulary $(p=0.26)$, Similarities $(p=0.95)$, Arithmetic $(p=0.79)$, Digit span $(p=0.06)$, Information ( $p=0.55)$, Comprehension ( $p=0.38$ ), Letter-number sequencing $(p=0.06)$, Picture completion $(p=0.47)$, Block design $(p=0.86)$, Matrix reasoning $(p=0.62)$, Picture arrangement $(p=0.97)$, Symbol search $(p=0.30)$ and Object assembly $(p=0.25)$ was not significantly different in the ASD group compared to the control group. For Digit symbol-coding, a significant difference emerged $(p=0.01)$. The control group outperformed the ASD group on this subtest.

\section{Discussion}

The aim of this study was to examine the WAIS-III performance of elderly persons with ASD and compare this to a neurotypical group of elderly adults. The results showed that the two groups did not differ in full scale intelligence, verbal comprehension, perceptual organization and working memory. A significant difference was found in processing speed, with the neurotypical group outperforming the elderly adults with ASD. On subtest level, performance was mostly comparable in the two groups, except for the subtest Digit symbol-coding. The elderly group with ASD showed weaker performance on this particular subtest.

With regard to full scale intelligence, the similarity between the ASD and the control group is striking, with less than three points difference. Based on the cognitive and behavioral impairment that characterize ASD, we expected to find that elderly individuals with ASD would 'need' a higher overall intelligence than neurotypical people in order to accomplish a certain educational level. This unexpected finding may be related to the high level of functioning of the ASD group in our study. From previous studies, we know that individuals with ASD who have a high level of intelligence often learn to compensate for their impairments $[4,13,17]$. This may have resulted in good performance at school for the individuals with ASD in our group. The compensation opportunities may 
Spek et al., Journal of Autism 2017,

http://www.hoajonline.com/journals/pdf/2054-992X-4-3.pdf

doi: 10.7243/2054-992X-4-3

Table 4. Mean standardized subtest scores.

\begin{tabular}{llll}
\hline & ASD $(\mathbf{N}=23)$ & Control (N=23) & Statistic \\
\hline Vocabulary & $10.3(2.8)$ & $11.1(2.1)$ & $F(1,44)=1.287, p=0.263$ \\
Similarities & $11.7(2.5)$ & $11.7(2.1)$ & $F(1,44)=0.004, p=0.950$ \\
Arithmetic & $11.7(3.0)$ & $11.5(2.5)$ & $F(1,44)=0.071, p=0.790$ \\
Digit Span & $11.0(3.1)$ & $12.7(2.9)$ & $F(1,44)=3.666, p=0.062$ \\
Information & $12.5(2.4)$ & $12.9(2.0)$ & $F(1,44)=0.355, p=0.554$ \\
Comprehension & $11.4(2.3)$ & $12.0(2.0)$ & $F(1,44)=0.794, p=0.378$ \\
Letter-Number Sequencing & $10.6(3.2)$ & $12.3(2.8)$ & $F(1,44)=3.860, p=0.056$ \\
Picture Completion & $10.4(2.6)$ & $9.8(2.6)$ & $F(1,44)=0.540, p=0.466$ \\
Digit-Symbol Coding & $9.9(3.2)$ & $12.0(2.3)$ & $F(1,44)=6.703, p=0.013^{*}$ \\
Block Design & $11.8(3.5)$ & $11.6(3.1)$ & $F(1,44)=0.032, p=0.859$ \\
Matrix Reasoning & $12.0(2.8)$ & $11.7(2.5)$ & $F(1,44)=0.253, p=0.617$ \\
Picture Arrangement & $10.5(3.7)$ & $10.4(3.3)$ & $F(1,44)=0.002, p=0.966$ \\
Symbol Search & $10.0(3.3)$ & $10.8(1.8)$ & $F(1,44)=1.125, p=0.295$ \\
Object Assembly & $11.5(3.6)$ & $10.5(2.0)$ & $F(1,44)=1.355, p=0.251$ \\
\hline
\end{tabular}

${ }^{\star} \mathrm{p}<0.05 ;{ }^{* *} \mathrm{p}<0.01$

also have influenced performance in other life areas, as is apparent in the general characteristics of our elderly ASD group. For instance, most of them were married and many have had jobs. Impairments do seem present in these individuals, but at a more subtle level.

For example, of the 17 individuals with ASD who have a relationship, 14 reported partner relational problems. Furthermore, one third of the ASD group was not able to find jobs on their educational level. Thus, although the high level of intelligence of the elderly with ASD may have resulted in a high level of attainted education, the impairments that characterize ASD did impede them in other areas of life. We would argue that they did relatively well in a structured environment (school), while experiencing more problems in situations that are less clear and structured, like a home situation with wife and children.

Despite the unimpaired global intelligence, the results of our study did indicate impairment in processing speed in the individuals with ASD. This is in line with previous findings in adults with ASD [24]. In this previous study, 45 adults with Asperger syndrome and 45 adults with an autistic disorder were compared with 45 neurotypical adults. Results showed impairment in processing speed in the adults with the autistic disorder [24]. Apparently, processing speed impairment of adults with ASD continues into old age.

Impairment in the processing speed index scale may be attributed to different underlying factors. For example, visual-motor coordination, visual-spatial analysis and working memory have all been hypothesized to be of influence on processing speed performance $[6,14]$. Also, impairment on processing speed subtests may be due to problems with top-down processing and weak central coherence, which are characteristic forASD $[\mathbf{9 , 2 2}]$.

In order to gain more insight into the underlying factors of the processing speed impairment of the elderly with ASD, results on subtest level may be of interest. Our data showed impairment on the subtest Digit symbol-coding (DSC), but unimpaired performance on Symbol search (SS). In adults with ASD, a reverse pattern was found, with impairment on SS but not on DSC [24]. This may point to different underlying factors of processing speed impairment in adults and in elderly persons with ASD. Both subtests have in common that they require the subject to focus attention, scan simple information quickly and order visual information sequentially using visual-motor coordination. The two subtests differ in that SS is usually performed using one strategy throughout the task (visual scanning), while most people change strategy during DSC [6]. The DSC subtest requires the subject to enter a simple symbol below each number in a long series. The look-up code for each number is printed at the top of the page. Usually, an incidental learning process emerges, in which the participants increasingly rely on rote memorization of which symbol goes with which number. In other words, they change strategy from checking each number on the sheet, to memory-based reactions.

Clinical observations during test performance showed that the individuals with ASD often kept checking each number; they did not rely on rote memorization. When being asked why, examples of remarks are: 'I don't want to make any mistakes' or 'I want a perfect result'. Although this topic needs further examination, a relationship may be hypothesized between performance of the elderly with ASD on the DGC subtest and increased attention to detail, which characterizes ASD [9]. Furthermore, changing strategy from checking to memorybased reactions may also be difficult for people with ASD because of impairment in cognitive flexibility and set shifting and a tendency to perseverate, which have been described as characteristic for ASD [18]. This is in line with findings of 
a previous study in college students, in which performance on the DGS subtest appeared more related to cognitive set shifting than to visual attention and motor speed [6]. Therefore, we hypothesize that processing speed impairment in the elderly with ASD is related to their tendency to persevere in a local strategy and to their difficulty changing to a global strategy. The lack of impairment on the SS subtest gives rise to the hypothesis that elderly individuals with ASD are not primarily impaired in motor speed and visual scanning abilities.

Apart from the Digit symbol-coding subtest, no further impairment appeared in the intelligence profiles of the elderly with ASD. Apparently, the general cognitive capacities of elderly people with ASD are relatively intact. If older individuals are still impaired in their theory of mind, executive dysfunction and central coherence, which is currently under debate [8], this would hardly seem to influence their intelligence profiles. This supports the hypothesis, postulated by [10], that people with ASD continue to develop skills throughout their life, which helps them to compensate for their impairments. In conclusion, general cognitive abilities of elderly people with ASD seem relatively in tact, when compared to a neurotypical elderly group. Analysis of group characteristics showed that impairments of older individuals with ASD are still present in their daily life functioning, but on a more subtle level. Furthermore, the results point to impairment in processing speed, which may be related to problems in set shifting and to a local information processing style, which are both characteristic forASD.

\section{Limitations}

There are several limitations of this study that should be taken into account in follow-up studies.

First, the present study was undertaken in elderly males with average to high intelligence. Therefore, the results from this study cannot be generalized to older male ASD groups with below average intelligence or to female individuals with ASD.

Secondly, the relatively small sample size of our study reduced the power to find effects and may have increased Type I error. Thirdly, due to the age of the participants with ASD, information about early childhood was not always available. This may have affected the reliability of the diagnoses, therefore the findings remain inconclusive. Fourth, we did not screen for thyroid, vitamin B12, folic acid or other common medical disorders that can affect cognitive performance, nor did we have previous baseline measures of processing speed for comparison.Therefore, it is important that future studies will expand upon our preliminary results, using a more definitive neuropsychological battery and neuro imaging measures.

Lastly, most of the participants with ASD received their autism diagnosis in late adulthood. Therefore, the results of this study may not be representative for ASD populations who have been diagnosed early in life.

\section{Competing interests}

The authors declare that they have no competing interests.

\section{Authors' contributions}

\begin{tabular}{|l|c|c|c|}
\hline Authors' contributions & AAS & LMH & FEMG \\
\hline Research concept and design & $\checkmark$ & -- & -- \\
\hline Collection and/or assembly of data & $\checkmark$ & $\checkmark$ & $\checkmark$ \\
\hline Data analysis and interpretation & $\checkmark$ & -- & $\checkmark$ \\
\hline Writing the article & $\checkmark$ & -- & $\checkmark$ \\
\hline Critical revision of the article & $\checkmark$ & $\checkmark$ & -- \\
\hline Final approval of article & $\checkmark$ & $\checkmark$ & $\checkmark$ \\
\hline Statistical analysis & $\checkmark$ & $\checkmark$ & -- \\
\hline
\end{tabular}

Acknowledgement

Thanks go to the adults who participated in the study and to all colleagues in Eindhoven who assisted in the study. Special thanks goes to Danielle van Hout for her assistance in collecting the data, to Rosalien Wilting for her advice and to Lannie Rozema for providing language help.

\section{Publication history}

Editor: Larry Jarrett Barnhill, University of North Carolina at Chapel Hill, USA.

Received: 16-Feb-2017 Final Revised: 22-Mar-2017

Accepted: 07-Apr-2017 Published: 21-Apr-2017

\section{References}

1. American Psychiatric Association Diagnostic and statistical manual of mental disorders (4th ed.),. text revision. Washington, DC: American Psychiatric Association. 2000.

2. American Psychiatric Association. DSM-5 Development. 2012.

3. Arnau RC and Thompson B. Second-order confirmatory factor analysis of the WAIS-III. Wechsler Adult Intelligence Scale. Assessment. 2000; 7:237-46. | Article | PubMed

4. Billstedt E, Gillberg IC and Gillberg C. Autism in adults: symptom patterns and early childhood predictors. Use of the DISCO in a community sample followed from childhood. J Child Psychol Psychiatry. 2007; 48:1102-10. | Article | PubMed

5. Catani M, Jones DK, Daly E, Embiricos N, Deeley Q, Pugliese L, Curran S, Robertson D and Murphy DG. Altered cerebellar feedback projections in Asperger syndrome. Neuroimage. 2008; 41:1184-91. | Article | PubMed

6. Davis AS and Pierson EE. The relationship between the WAIS-III digit symbol Coding and executive functioning. Appl Neuropsychol Adult. 2012; 19:192-7. | Article | PubMed

7. Frith U. Autism. Explaining the enigma. Oxford: Blackwell Publishing. 1989.

8. Geurts HM and Vissers ME. Elderly with autism: executive functions and memory. J Autism Dev Disord. 2012; 42:665-75. | Article | PubMed Abstract | PubMed FullText

9. Happé F.G.E. The weak central coherence account of autism. In: Volkmar, F.R., Rhea, P., Klin, A., \& Cohen, D., editors. Handbook of autism and pervasive developmental disorders. New Jersey: John Wiley \& Sons. 2005; 772-798.

10. Happe $\mathrm{F}$ and Charlton RA. Aging in autism spectrum disorders: a minireview. Gerontology. 2012; 58:70-8. I Article I PubMed

11. Hill E.L. Evaluating the theory of executive dysfunction in autism. Developmental Review. 2004; 24:189-233. I Pdf

12. Howlin P, Goode S, Hutton J and Rutter M. Adult outcome for children with autism. J Child Psychol Psychiatry. 2004; 45:212-29. | Article | PubMed

13. James IA, Mukaetova-Ladinska E, Reichelt FK, Briel R and Scully A. Diagnosing Aspergers syndrome in the elderly: a series of case presentations. Int J Geriatr Psychiatry. 2006; 21:951-60. | Article | 
Spek et al., Journal of Autism 2017,

http://www.hoajonline.com/journals/pdf/2054-992X-4-3.pdf

PubMed

14. Kaufman A.S and Lichtenberger E.O. Assessing adolescent and adult intelligence ( $3^{\text {rd }}$. ed.). Hoboken, New York: John Wiley. 2006.

15. Lord C, Rutter M and Le Couteur A. Autism Diagnostic Interview-Revised: a revised version of a diagnostic interview for caregivers of individuals with possible pervasive developmental disorders. J Autism Dev Disord. 1994; 24:659-85. I PubMed

16. Mawhood L, Howlin P and Rutter M. Autism and developmental receptive language disorder--a comparative follow-up in early adult life. I: Cognitive and language outcomes. J Child Psychol Psychiatry. 2000; 41:547-59. | Article | PubMed

17. Naidu A, James I, Mukaetova-Ladinska $E$ and Briel R. Diagnosis of Asperger syndrome in a 66-year-old male presenting with depression. Int Psychogeriatr. 2006; 18:171-3. | Article | PubMed

18. Rumsey JM and Hamburger SD. Neuropsychological findings in high-functioning men with infantile autism, residual state. J Clin Exp Neuropsychol. 1988; 10:201-21. | Article I PubMed

19. Ryan JJ and Paolo AM. Exploratory factor analysis of the WAIS-III in a mixed patient sample. Arch Clin Neuropsychol. 2001; 16:151-6. | Article I PubMed

20. Sattler J.M and Ryan J.J. Assessment of children, revised: WAIS-III supplement. LeMesa, CA: Jerome Sattler Publishing. 1999.

21. Seltzer MM, Shattuck P, Abbeduto L and Greenberg JS. Trajectory of development in adolescents and adults with autism. Ment Retard Dev Disabil Res Rev. 2004; 10:234-47. | Article | PubMed

22. Shah $A$ and Frith $U$. Why do autistic individuals show superior performance on the block design task? J Child Psychol Psychiatry. 1993; 34:1351-64. | Article | PubMed

23. Spek AA, Scholte EM and van Berckelaer-Onnes IA. Brief report: The use of WAIS-III in adults with HFA and Asperger syndrome. J Autism Dev Disord. 2008; 38:782-7. | Article | PubMed Abstract | PubMed FullText

24. Spek A.A, Scholte E.M and van Berckelaer-Onnes I.A. Cognitive characteristics of adults with the autistic disorder and Asperger syndrome with regard to WAIS III profiles (Cognitievekenmerken van volwassenen met de autistischestoornisen de stoornis van Asperger aan de hand van WAIS-III profielen). GZ-psychologie. 2009; 1:24-29.

25. Sundaram SK, Kumar A, Makki MI, Behen ME, Chugani HT and Chugani DC. Diffusion tensor imaging of frontal lobe in autism spectrum disorder. Cereb Cortex. 2008; 18:2659-65. | Article | PubMed Abstract | PubMed FullText

26. Wechsler D. WAIS-III. Dutch translation. Technical manuall Nederlandstalige bewerking. Technische handleiding.) Lisse: Swets\&Zeitlinger. 2000.

27. Wechsler D. WAIS-III. Dutch translation. Technical manual, revised edition. (Nederlandse bewerking. Technische handleiding, herziene uitgave 2005). Amsterdam: Harcourt Test Publishers. 2005.

28. Witwer AN and Lecavalier L. Examining the validity of autism spectrum disorder subtypes. J Autism Dev Disord. 2008; 38:1611-24. | Article | PubMed

\section{Citation:}

Spek AA, Ham LM and Geven FEM. The intellectual profiles of high functioning elderly persons with an autism spectrum disorder. J Autism. 2017; 4:3.

http://dx.doi.org/10.7243/2054-992X-4-3 